\title{
O ensino remoto de língua portuguesa na educação básica frente à pandemia da COVID-19: perspectivas e possibilidades
}

Remote teaching of Portuguese language in basic education in front of the COVID-19 pandemic: perspectives and possibilities

\author{
Ive Marian de Carvalho \\ Universidade Federal do Ceará - UFC - Ceará - Brasil
}

Pollyanne Bicalho Ribeiro

Universidade Federal do Ceará - UFC - Ceará - Brasil

\begin{abstract}
Resumo: Estamos vivenciando, no ano de 2020, um momento sem precedentes em nosso país, onde o isolamento social se faz necessário devido à pandemia de coronavírus que cresce a passos largos diariamente. Diante deste cenário, no qual as escolas encontram-se impossibilitadas de desenvolver atividades presenciais, redes estaduais e municipais de ensino de todo o país e escolas particulares buscam alternativas para que as aulas continuem acontecendo. $O$ ensino remoto, através de meios virtuais, vem se mostrando a melhor alternativa até o momento, embora possua limitações que não devem ser desconsideradas. Através do trabalho remoto com a Língua Portuguesa, é possível desenvolver multiletramentos e a construção da identidade do aluno, reforçando seu papel ativo em uma sociedade cada vez mais tecnológica e visual. O papel do professor continua sendo de extrema importância na estrutura remota, bem como do núcleo gestor, principalmente para buscar minimizar quadros de desigualdade educacional, assegurando que as atividades e as tecnologias escolhidas contemplem também aqueles alunos que se encontram em situação de vulnerabilidade extrema.
\end{abstract}

Palavras-chave: Ensino remoto. Língua Portuguesa. Pandemia.

Abstract: We are facing, in the year 2020, an unprecedented moment in our country, where social isolation is necessary due to the coronavirus pandemic that is growing at a fast pace daily. Given this scenario, in which schools are unable to develop presential activities, state and municipal education networks across the country and private schools are looking for alternatives so that classes can continue to take place. Remote teaching through virtual media has been shown to be the best alternative so far, although it has limitations that should not be disregarded. Through remote work with the Portuguese language, it is possible to develop multiliteracy and the construction of the student's identity, reinforcing their active role in an increasingly technological and visual society. The role of the teacher continues to be extremely important in the remote structure, as well as in the management nucleus, mainly to seek to minimize frames of educational inequality, ensuring that the activities and technologies chosen also include those students who are in a situation of extreme vulnerability.Keywords: Remote teaching. Portuguese Language. Pandemic.

Keywords: Remote teaching. Portuguese Language. Pandemic. 


\section{Introdução}

Sabemos que estamos vivendo em meio a uma pandemia de coronavírus, situação nova e bastante desafiadora que está sendo motivo de muita preocupação por parte de diversos setores, não só no Brasil como no mundo. As pessoas estão sendo orientadas a evitar aglomerações e a sair de casa o mínimo possível, diminuindo, assim, o risco de transmissão e contágio da COVID-19; não se sabe ainda ao certo quando estes cuidados deixarão de ser necessários.

No que se refere à educação, a pandemia da COVID-19 resultou na interrupção do funcionamento das escolas públicas e particulares, com a substituição, por assim dizer, das aulas presenciais por atividades remotas. Segundo a Unesco e a Unicef (BRASIL, 2020), 91\% dos alunos no mundo inteiro estão temporariamente fora da escola.

Neste cenário, as redes estaduais, municipais, secretarias de educação, gestores escolares e professores buscam viabilizar o estudo domiciliar dos alunos da educação básica, através do uso de plataformas digitais e redes sociais e da elaboração de materiais e aulas ao vivo. Além do papel importante desempenhado pelos professores, gestores e secretarias de educação, a família possui fundamental importância neste momento, incentivando e acompanhando os estudos domiciliares, além do próprio aluno, que pode aproveitar esse momento para desenvolver uma postura autônoma em relação a seus estudos.

Frente a essa nova realidade, faz-se necessário pensar em estratégias adequadas ao ensino remoto que, como bem sabemos, apresenta diversas vantagens, porém muitos desafios e limitações. É preciso reconhecer que estamos enfrentando uma situação sem precedentes na história de nosso país, o que exige do poder público educacional a tomada de decisões rápidas e precisas em relação a problemáticas complexas e inéditas (BRASIL, 2020). Além disso, neste momento, não é possível pensar no ensino à distância de maneira retrógrada e tradicionalista, onde ele se antagoniza às aulas presenciais, haja vista que as atividades remotas vêm se mostrando a opção mais viável para que as aulas continuem acontecendo. Como afirma Kamenetz (2020), caso o poder público escolha nada fazer, sob a justificativa de que não é possível atingir a todos os alunos, sobretudo aos de regiões mais pobres onde a tecnologia ainda parece ser algo muito distante, acabará por contribuir para que as desigualdades resultantes de uma situação de emergência cresçam de forma exponencial.

\section{O componente curricular Língua Portuguesa} no ensino remoto

Por ser, como já dissemos, uma situação sem precedentes e ainda bastante recente no país, ainda não há muitos estudos aprofundados sobre as possibilidades do trabalho remoto de componentes curriculares específicos da educação básica. Proporemos, aqui, algumas discussões e possibilidades acerca do trabalho com a Língua Portuguesa nesse contexto, que podem ser revistas e ampliadas em trabalhos posteriores.

Segundo Barros e Crescitelli (2008), a tecnologia, por si só, não é capaz de solucionar todas as problemáticas da educação. Mais do que somente saber o que fazer, é importante saber como fazer. Ainda segundo os autores, "a EaD via computador, por si só, não é nem melhor nem pior do que o ensino presencial" (p.73). Contudo, ela exige um planejamento específico para que se saiba exatamente o que fazer e se faça bem feito. É preciso pensar em uma interação virtual diferente da presencial, onde o professor não seja o único foco das atenções e este passe a assumir o papel de mediador do processo de aprendizagem, gerenciando interações múltiplas, a partir de gêneros textuais diversos, garantindo que o aluno se sinta "mais à vontade num ambiente virtual que ele de modo geral desconhece, além de fazê-lo se apropriar de gêneros textuais com os quais não está acostumado a lidar" (BARROS E CRESCITELLI, 2008, p.77).

É preciso um novo olhar sobre a EaD para que de fato possamos alcançar um ensino produtivo capaz de promover (trans)formações significativas em nossa sociedade atual. Por vezes, a EaD é avaliada a partir das referências que temos da educação presencial, ou 
seja, há uma busca incessante de suprir as ausências deixadas pelo aspecto não presencial da modalidade, quando, na verdade, deveríamos perceber as suas possibilidades, as suas especificidades, os seus recursos. As possibilidades do letramento em âmbitos semióticos, que podem ser entendidos como "qualquer conjunto de práticas que utilize uma ou mais modalidades (por exemplo, linguagem oral ou escrita, imagens, equações, símbolos, sonidos, gestos gráficos, artefatos etc.) para comunicar tipos característicos de significados" (GEE, 2004, p. 22), devem compor os espaços da prática formativa pelo seu potencial atrativo entre os alunos e, portanto, para fomentar o desenvolvimento objetivado na esfera escolar.

Quanto ao letramento em ambiente virtual, a própria representação de texto tradicional deve ser revista, ampliada, ressignificada, pois, o hipertexto, "conjunto de nós ligados por conexões" (LĖVY, 1993, p. 33), assume um caráter dinâmico, interativo e desprovido de uma ordem hierárquica entre as informações. O ensino de Língua Portuguesa, então, deve levar em conta os nós, as interseções, a rede de informações instaurada pelo ambiente virtual. Assume-se, então, o desafio de considerar a navegação como uma ação profícua de aprendizagem, como uma aliada ao processo formativo.

Em consonância com esse pensamento, 0 ensino de Língua Portuguesa desenvolvido por atividades remotas pode corroborar para 0 aprimoramento de multiletramentos e para a construção da identidade do aluno, a partir da autonomia que terá de desenvolver para estudar em casa de maneira eficiente.

Rojo (2012) afirma que não é mais possível pensar no termo cultura sob uma visão centralizada; é preciso concebê-lo sob uma ótica "desessencializada de cultura(s)". Dessa forma, os multiletramentos apontam para a multiplicidade e variedade das práticas letradas, valorizadas ou não nos diversos âmbitos da sociedade.

A multiplicidade das linguagens, facilmente percebida nos diferentes gêneros do discurso que circulam na sociedade contemporânea, refere-se, segundo Rojo (2012) a "textos compostos de muitas linguagens (ou modos, ou semioses) e que exigem capacidades e práticas de compreensão e produção de cada uma delas (multiletramentos) para fazer significar". Os multiletramentos, segundo Magnani (2011), inauguram uma nova concepção de ensino e relação com a língua, na qual o sujeito não assimila de forma passiva os conhecimentos e conteúdos, mas os articula a seus conhecimentos prévios, trajetória e interesses. Este sujeito, assim, participa ativamente da constante transformação da sociedade.

O aluno, envolvido com a leitura e escrita no universo virtual, poderá ampliar seu acervo de conhecimentos, adquirir habilidades para construir sentido(s) a partir de hipertextos e, por assim ser, desenvolver multiletramentos. Nesse locus de aprendizagem, os sujeitos são motivados a relacionarem distintas mídias, a trocarem informações e habilitarem-se como protagonistas de seu desenvolvimento.

Neste cenário de intensas transformações sociais, a palavra escrita passou a ser considerada apenas como parte da mensagem. Juntamente com ela, outros elementos advindos de outros sistemas simbólicos compõem o corpo do texto como um todo (DESCARDECI, 2002). A presença maciça das imagens nas práticas de escrita abre espaço para as mudanças no discurso e coloca em evidência principalmente a linguagem visual. Sobretudo com a criação do cinema, da TV e, principalmente, da internet, a comunicação tornou-se mais rápida e repleta de elementos visuais. As imagens, atualmente, possuem presença quase que obrigatória em nossas práticas comunicativas, o que acarreta em um novo discurso semiótico, onde imagem e texto verbal se unem na construção de novos sentidos, os chamados gêneros multimodais.

Quanto mais familiarizado com os gêneros, maior a possibilidade de o sujeito se envolver em uma produção e compreensão exitosa. Isso porque ele se valerá de um repertório linguístico, textual e discursivo que o permitirá fazer as melhores escolhas para compreender ou produzir um texto. Dionísio (2010, 
p.164-165) chama atenção para o impacto trazido pela tecnologia na produção de gêneros.

O dinamismo da imagem do filme passou para a charge virtual, para 0 pôster interativo, a disposição do texto na página oscila entre os moldes ocidentais e orientais de escrita; estes são apenas alguns exemplos que deixam transparecer a necessidade de revisão do conceito de leitura e de suas estratégias que utilizamos em nossas aulas. Consequentemente, se os gêneros se materializam em formas de representação multimodal (linguagem alfabética, disposição gráfica na página ou na tela, cores, figuras geométricas etc.) que se integram na construção do sentido, o conceito de letramento também precisa ir além do meramente alfabético. Precisamos falar em multiletramento! (DIONÍSIO, 2010, p.164-165)

Assim, as diversas semioses disponibilizadas nas práticas sociais cada vez mais compõem os gêneros e devem ser tematizadas em sala de aula. De acordo com Rojo (2012, p. 19), a multimodalidade diz respeito a "textos compostos de muitas linguagens (ou modos, ou semioses) e que exigem capacidades e práticas de compreensão e produção de cada uma delas (multiletramentos) para fazer significar".

De acordo com a referida autora (2012, p.23), são características dos multiletramentos:

(a) Eles são interativos; mais que isso, colaborativos;

(b) Eles fraturam e transgridem as relações de poder estabelecidas, em especial as relações de propriedade (das máquinas, das ferramentas, das ideias, dos textos - verbais ou não);

(c) Eles são híbridos, fronteiriços, mestiços (de linguagens, modos, mídias e culturas)

Vê-se, portanto, o quanto os gêneros podem nos possibilitar compreender a dinâmica social e, por sua vez, as relações intrapessoais e interpessoais processadas em uma determinada prática, aqui, particularmente, a prática dos multiletramentos.

Em consonância com essa prática, a BNCC contempla as seguintes áreas do conhecimento: 1) Linguagens, 2) Matemática, 3) Ciências da Natureza e 4) Ciências Humanas, sendo que cada uma delas têm competências específicas de área - reflexo das dez competências gerais da BNCC - que devem ser promovidas ao longo de todo o Ensino Fundamental.
As competências específicas possibilitam a articulação horizontal entre as áreas, perpassando todos os componentes curriculares, e também a articulação vertical, ou seja, a progressão entre o Ensino Fundamental - Anos Iniciais e o Ensino Fundamental - Anos Finais e a continuidade das experiências dos alunos, considerando suas especificidades (BNCC, 2017). Entre os componentes curriculares presentes na BNCC, o componente Língua Portuguesa - da área de Linguagens - não está estruturado em unidades temáticas. Ou seja, ela se organiza em práticas de linguagem (leitura/escuta, produção de textos, oralidade e análise linguística/semiótica), campos de atuação, objetos de conhecimento e habilidades.

Os Campos de Atuação propostos pela BNCC contribuem para garantir a contextualização das práticas de linguagem: da vida cotidiana; da vida pública; das práticas de estudo e pesquisa; do artístico/literário.

A definição dos campos de atuação contribui para o ensino da língua contextualizado, conforme os pressupostos do letramento, visto que haverá possibilidade de um trabalho focado nos textos reais que são produzidos nessas práticas sociais. Segundo Bakhtin (2003), os gêneros primários, encontrados nas esferas privadas, são menos complexos, menos estruturados e mais suscetíveis a mudanças; já os gêneros secundários, encontrados na esfera pública, são mais complexos, automatizados e menos dados a mudanças. Os campos de atuação abordados pela BNCC demonstram o movimento do continuum entre as esferas privadas e públicas, tematizadas pelo Círculo de Bakhtin.

Bakhtin/Volóchinov (2004, p. 126) dispõe a respeito das implicações da forma-padrão de determinados gêneros para um determinado propósito comunicativo face ao auditório social ao qual esse gênero se dirige.

Toda situação inscrita duravelmente nos costumes possui um auditório organizado de uma certa maneira corrente. A fórmula estereotipada adapta-se, em qualquer lugar, ao canal de interação social que lhe é reservado, refletindo ideologicamente o tipo, a estrutura, os objetivos e a composição 
social do grupo.

(BAKHTIN/VOLÓCHINOV, 2004, p. 126)

Formas de dizer organizam o nosso agir comunicativo em sociedade, há a emergência de gêneros a partir das configurações disponibilizadas pelos campos de atuação. Nesses campos, é recorrente, por exemplo, depararmos com textos compostos por diferentes semioses, já que "ao lermos um texto manuscrito, um texto impresso numa página de revista, ou na tela de um computador, estamos envolvidos numa comunicação multimodal. (DIONíSIO, 2005, p. 178).

O letramento multimodal é de fundamental importância para a nossa inserção em um mundo no qual significados emergem de maneira translocal, multicultural e híbrida (COPE; KALANTZIS, 2000). A educação, então, deve se voltar para formação de alunos capazes de compreender, produzir e transformar significados linguísticos, visuais, de áudio, gestuais e espaciais nos diversos campos de atuação de nossa sociedade.

Diante desse contexto, é possível constatar que a atual sociedade é multimodal, onde recursos visuais tornaram-se comuns e a imagem serve como simulação do mundo real, ilustrando discursos, visões ou posicionamentos.

Os letramentos da realidade virtual, como denomina Lemke (2010), vão além dos letramentos e conhecimentos humanos. $\mathrm{O}$ autor defende que, com 0 advento e a democratização da tecnologia digital, professores e alunos precisam aprender a lidar com os diversos recursos tecnológicos a seu alcance, pois recursos multimodais possuem especial relevância para que os alunos sejam capazes de produzir sentidos, além de exercer funções comunicativas que antes somente a escrita poderia ser capaz de realizar.

O trabalho com a Língua Portuguesa através de atividades remotas pode auxiliar não apenas nesse processo de apropriação de recursos multimodais para a produção de sentidos, mas também permite o contato direto com gêneros multimodais que não são tão explorados em contextos escolares, seja pela predileção por gêneros tradicionalmente ligados a avaliações externas ou pelo fato de a escola não ter aparelhos tecnológicos suficientes para todos os alunos. Segundo Marcuschi (2007), os gêneros são fenômenos históricos profundamente vinculados à vida cultural e social. São eventos textuais maleáveis e dinâmicos, que surgem de acordo com as necessidades socioculturais, como se pode perceber na quantidade de gêneros hoje existentes a partir das inovações tecnológicas. Atualmente, na era da cultura digital e a invenção de novas formas de comunicação, como a TV, o celular e, principalmente, a internet, surgiu um grande número de novos gêneros, tanto escritos quanto orais. O autor chama ainda a atenção para a importância de se pensar num ensino baseado em gêneros que atente para aspectos mais ligados à realidade do aluno, ao invés de focar apenas em gêneros mais recorrentes na esfera escolar (MARCUSCHI, 2011).

O trabalho com a Língua Portuguesa de forma remota permite que os alunos entrem em contato com gêneros como o podcast, o curta-metragem, o fórum de discussão, os chats, o e-mail, a videoaula, dentre outros, que não encontram muito espaço no ambiente escolar, mas que são extremamente necessários para a formação de um aluno consciente na utilização da linguagem como prática social, enquanto estabelece relações com 0 contexto, seus papéis constitutivos e propósitos comunicativos. Como apontam estudos na área nos últimos anos, o ensino a partir de gêneros possibilita a compreensão do mundo e de sua estrutura organizacional. A partir do domínio de gêneros diversos e de interações verbais, o indivíduo é capaz de promover transformação social. Segundo Miller (2009), ao dominarmos um gênero, aprendemos formas típicas de expressão para fins específicos e, além disso, que propósito podemos alcançar, tais como interagir, criticar ou influenciar pessoas, por exemplo. Dessa forma, possibilita-se ao aluno participar ativa e criticamente das ações de sua comunidade (MARCUSCHI, 2003).

O papel do professor na estrutura remota e o combate às desigualdades educacionais

Em relação ao estudo remoto no atual cenário pandêmico, há, ainda, algumas questões importantes a serem consideradas. A primeira diz respeito ao papel do professor nesse contexto, que continua sendo essencial, ainda que as atividades escolares estejam sendo desenvolvidas em casa. Pesquisas (BRASIL, 2020) apontam que estratégias de ensino remoto que não envolvem a atuação do professor possuem menos alcance e menos engajamento por parte dos alunos. Sabe-se que grande parte dos professores brasileiros carecem de aperfeiçoamento profissional para o uso 
pedagógico de tecnologias educacionais; além disso, há questões que estão diretamente relacionadas ao isolamento social, como os impactos na saúde mental, falta de motivação para a realização das atividades domiciliares e problemas na gestão do tempo. A escolha das tecnologias a serem utilizadas devem levar em consideração essas problemáticas e o poder público deve se mobilizar para que os professores recebam a formação, o apoio e as orientações necessárias à superação dos desafios educacionais que se apresentam atualmente e que, provavelmente, continuarão a existir.

Para que de fato a EaD cumpra o seu propósito é preciso que haja interação, diálogo, pois, caso contrário, o que iremos ter é instrução e não educação a distância. Sabemos que devemos nos valer de toda sorte de recursos digitais para que se instaure um ambiente dialógico de aprendizagem (fóruns, chats, glossários, bloco de comentários, etc.), mas o papel do professor, compreendido como mediador, é imprescindível para que se cumpra os objetivos pedagógicos traçados. Instaurar, portanto, uma relação horizontal entre professor e aluno se faz necessário para as trocas de saberes, para dirimir eventuais dúvidas surgidas na relação ensino e aprendizagem.

No entanto, como o ambiente virtual se configura de traços específicos, devemos conhecer a sua estrutura e funcionamento para operarmos com a diversidade das ferramentas disponibilizadas para esse ambiente, visto que a internet "desestabiliza algumas de nossas crenças, porque gera mudanças em regras socialmente convencionadas que dizem respeito aos papéis que cada ator 'pode' ou 'deve' desempenhar no processo de produção de conhecimento" (SOUTO; BORBA, 2016, p. 2). Vale salientar que, para conhecer as potencialidades do ambiente para a prática formativa e para atualizar crenças cristalizadas, devemos ter ações formativas para todos os sujeitos envolvidos na relação ensinoaprendizagem. Aos gestores, privados e públicos, caberá a oferta de contínuas formações a fim de informar e atualizar sobre aspectos relacionados à esfera virtual, suas possibilidades e limitações.

Um dos problemas que se apresenta ao professor é o acúmulo de papéis, pois, além de lecionar a disciplina, pode acabar exercendo outras funções dentro da EaD, sendo recorrente, em certas instituições de ensino, assumir o papel de tutor, de secretaria, de designer gráfico, entre outros, precarizando seu trabalho. Há um excesso de responsabilização da figura do professor quanto à abordagem do aluno no contexto virtual, se não houver atribuições claras sobre a função de cada um envolvido com a EAD (coordenadoria, tutoria, secretaria, financeiro etc.), o professor será demandado a responder questões que não lhe cabem, o que, é claro, prejudicaria a sua atuação na docência propriamente dita. As boas condições de trabalho devem ser garantidas para que tenhamos um ensino de qualidade em qualquer instância formativa.

Outro aspecto peculiar à EaD que devemos refletir é a gestão do tempo. É verdade que o tempo é relativamente plástico no contexto virtual, contudo, isso não quer dizer que a qualquer momento o professor poderá ser requisitado a exercer as suas funções. Ainda que haja uma maior imbricação do âmbito doméstico e profissional, devemos estabelecer limites, a jornada de trabalho não pode ser alongada, a profissão não pode sobrepor a outros papéis sociais a serem assumidos pelos professores. Nesse cenário, os professores precisam ser

bons gestores do tempo, desenvolvendo e adotando estratégias e práticas que aperfeiçoem o sistema, já que a natureza da educação a distância parece flexível em relação ao tempo, porque pode ser feito a qualquer hora em qualquer lugar, torna-se difícil o entendimento e a manipulação do mesmo, não só no que se refere à preparação da aula como à gestão diária das interações. (CAMAS, 2012, p.25)

Entretanto, ressaltamos que uma boa gestão do tempo só será factível se os atores e, sobretudo, os gestores envolvidos com a EaD entenderem que é preciso não sobrecarregar 0 profissional com reuniões infindáveis, realizadas remotamente, com excessos burocráticos, enfim, com demandas adicionais à carga horária contratada. Não é porque o professor trabalha em casa que não deve haver tempo para o descanso, para o planejamento, para a formação.

Ademais, há outra situação preocupante que se revelou no contexto da pandemia concernente ao comportamento dos pais dos alunos. Como os discentes estão em casa, às vezes, acompanhados pelos pais no momento das atividades virtuais, há um controle maior, uma espécie de inspeção sobre as escolhas teóricometodológicas empreendidas, muitas vezes, a aprovação ou não dessas escolhas passa por critérios ideológicos, 
políticos e não pedagógicos, colocando em xeque a autonomia docente. Não estamos aqui defendendo a não participação dos pais na prática formativa, pelo contrário, a comunidade escolar deve agir em benefício do processo educativo, mas o professor deve ter as suas prerrogativas profissionais preservadas, não pode estar suscetível a consequências de julgamentos e avaliações, por vezes, descabidos.

a implantação da informática como auxiliar do processo de construção do conhecimento implica mudanças na escola que vão além da formação do professor. É necessário que todos os segmentos da escola - alunos, professores, administradores e comunidades de pais - estejam preparados e suportem as mudanças educacionais necessárias para a formação de um novo profissional. Nesse sentido, a informática é um dos elementos que deverão fazer parte da mudança, porém essa mudança é mais profunda do que simplesmente montar laboratórios de computadores na escola e formar professores para utilização dos mesmos (VALENTE, 1999, p. 4).

Particularmente quanto ao professor de Língua Portuguesa, a internet trouxe uma pluralidade de gêneros, com discursos de vários campos: ético, religioso, cultural, político, etc., que nos impôs repensarmos sobre como promover formação que leve em conta mudanças de comportamentos, como, por exemplo, a não propagação de fake news, o respeito à opinião alheia e a preservação da face nas mídias sociais. A cultura digital se coloca como promotora de uma busca incessante de saberes, porque as novas tecnologias se renovam continuamente, exigindo competências e comportamentos adicionais ao que antes tínhamos na prática de ensino tradicional. Nesse sentido, devemos formar sujeitos na sua integralidade, leitores e produtores críticos de textos formulados nas mídias sociais.

Outra questão a ser considerada é a desigualdade social existente não apenas entre as redes de ensino do país, como também entre alunos da educação básica de uma mesma rede e, até mesmo, de uma mesma escola ou sala de aula. Faz-se necessário, diante desta realidade, avaliar a possibilidade de envio de materiais impressos, como livros ou atividades, além de se fazer um levantamento dos recursos tecnológicos de que os alunos dispõem, para que, dessa forma, não se penalize ainda mais os que se encontram em situação de vulnerabilidade. A baixa qualidade da conexão de internet em diversas regiões do país também deve ser levada em conta ao se escolherem conteúdos e equipamentos. Além disso, assim como a do professor, a saúde mental do aluno deve ser levada em consideração, suas condições de isolamento e o grau de envolvimento da família em seus estudos. Sabemos que tais medidas não são capazes de extinguir a problemática, mas podem auxiliar a não aprofundar as desigualdades de aprendizagem entre os alunos da educação básica.

\section{Uma proposta didática para o ensino remoto de} Língua Portuguesa

A escola da Educação Básica, geralmente, organiza-se na modalidade presencial, mas isso não significa que a prática educativa não possa ser múltipla, plural e permitir também experiência com tecnologia. No contexto da pandemia do Covid-19, o ambiente virtual se impôs como a única forma de garantir o ensino, ainda que, por vezes, de maneira precária, dadas as adversidades socioeconômicas já discutidas anteriormente. Salientamos que a competência digital atualmente deve ser parte do desenvolvimento da competência comunicativa, não há como prescindi-la em um mundo cada vez mais envolvido com tecnologias digitais.

$\mathrm{Na}$ tentativa de colaborar para a atuação docente no contexto virtual, propomos uma atividade que visa reunir os estudos da Linguística Aplicada com as possibilidades de ações comunicativas no ambiente da internet, favorecendo uma reflexão sobre o ensino de Língua Portuguesa e novas tecnologias, sobre teoria e prática no cotidiano escolar contemporâneo, reconhecendo as suas possibilidades e limitações.

A seguir, iremos expor o plano de aula da proposta de ensino remoto de Língua Portuguesa. Ressalta-se que, como todo plano, é possível flexibilizá-lo para atender melhor ao público-alvo e adequá-lo às condições dadas pelo contexto formativo ao qual a atividade irá se realizar. Sugere-se que este plano seja aplicado em qualquer ano do Ensino Médio. Salienta-se, no entanto que, com as devidas adaptações, é possível o desenvolvimento dessas atividades também no Ensino Fundamental.

Plano de aula

Título: Engajamento nas mídias sociais 


\section{Conteúdo: Argumentação}

Objetivo: Desenvolver o senso crítico e o engajamento através da tomada de posicionamento, efetuada de maneira polida, em relação a temas sociais relevantes veiculados nas mídias sociais.

\section{Procedimento:}

- A turma deverá escolher uma situação da realidade brasileira atual que demande um olhar crítico, uma tomada de posicionamento frente a esse acontecimento.

- Sugere-se que essa escolha seja feita previamente através de uma reunião no ambiente virtual (Meet, Zoom, Skype). Na ocasião, o(a) professor(a) poderá ler as principais manchetes de jornais do país, disponíveis na internet, a fim de promover a identificação de problemas sociais presentes na realidade brasileira. Após a discussão, os alunos, com a ajuda do(a) professor(a), comporão uma lista com os problemas que mais despertaram interesse de debater em sala de aula. Diante da listagem, a turma votará qual o problema gostaria de aprofundar a discussão ao longo das atividades a serem desenvolvidas.

- Os alunos, a partir da temática selecionada, deverão debater a respeito através de chats e fóruns. Os chats poderão ser estabelecidos com hora marcada para que todos participem. Quanto aos fóruns, o(a) professor(a) poderá tecer um breve comentário ou postar uma notícia a respeito do problema a ser debatido e, em seguida, abrir para os alunos postarem seus comentários. Ressalta-se que o(a) professor(a) deixará claro que os alunos deverão produzir comentários com força argumentativa e que respeitem a opinião dos demais colegas (polidez verbal). Deve-se ressaltar, logo no início da atividade, a importância de argumentar sobre a temática de maneira polida, demonstrando que o respeito ao outro é essencial para a preservação da face e, inclusive, para o êxito do projeto comunicativo.

- Para subsidiar as reflexões, o(a) professor(a) poderá disponibilizar textos (notícias, artigos científicos, charges, etc.), a fim de fomentar as discussões. $O(A)$ professor(a) poderá também solicitar aos alunos que pesquisem e postem os resultados sobre a temática.

- $O(A)$ professor(a) enquanto mediador(a), deve ficar atento(a) às escolhas linguísticas dos alunos ao expressarem a opinião sobre a temática.

- O(A) professor(a), valendo-se de exemplos postados no fórum, poderá expor, através de mais um encontro virtual (Meet, Zoom, Skype, etc.), a distinção entre fato e opinião, visto que, em geral, as pessoas tomam como fato a opinião alheia e compartilham postagens sem verificarem a veracidade da informação (curadoria virtual)
- Após a reflexão feita pelos chats e fóruns, solicitar aos alunos que pensem em uma postagem individual a ser feita no Facebook, mas a postagem deve ter no máximo 270 caracteres para que ele possa ser construído com cores e fontes diferentes.

- Ressaltar que a postagem deve ter força argumentativa, mas deve estar de acordo com a polidez verbal. Seria oportuno discutir com os alunos as melhores opções de cores, de fonte, de imagens etc., para garantir maior adesão à postagem. Para tanto, o(a) professor(a) poderá expor para a turma exemplo de postagens que avalia serem exitosas quanto à força argumentativa e à polidez verbal.

- Demonstrar alguns exemplos de posts que circulam nas páginas dessas mídias para que os alunos percebam os recursos verbais e não verbais. Salientar a importância da pontuação, dos jogos de linguagem (sobretudo, a ironia) para a argumentação. A exposição dos recursos linguísticos/discursivos, assim como os exemplos de postagens bem-sucedidas quanto ao projeto argumentativo podem ser exibidas para os alunos através de power point.

- Solicitar que façam um post sobre o assunto debatido e que postem em seus perfis na plataforma digital a que estão utilizando na $\mathrm{EaD}$ ou, se forem autorizados a usar as redes, postarem no Facebook, Twitter, Instagram.

- Propor uma reflexão, após um intervalo de tempo estabelecido, sobre a reação dos usuários da rede diante da postagem.

Recurso: Notebook ou celular ou tablet

Avaliação: $\mathrm{O}(\mathrm{A})$ professor(a), ao longo do processo, avaliará a capacidade de os alunos se engajarem de maneira respeitosa diante de algum acontecimento que suscite comoção, posicionamento.

\section{Considerações finais}

Por fim, é importante lembrar que, embora o ensino remoto apresente limitações bastante específicas, demonstra bastante relevância no atual momento que estamos enfrentando, onde é preciso cumprir o isolamento social e, portanto, as escolas precisam estar fechadas. Sabemos que ele não pode substituir o ensino presencial e que diversos alunos em situação de vulnerabilidade não têm muitos recursos tecnológicos à disposição, porém, se nada for feito, as desigualdades educacionais serão ainda maiores. 
O trabalho com gêneros é de fundamental importância, haja vista que o sujeito, quanto mais familiarizado com eles, mais chances terá de se envolver em uma produção e compreensão exitosa, pois terá ao seu dispor repertório linguístico, textual e discursivo que permitirá que faça melhores escolhas ao compreender ou produzir um texto.

A Língua Portuguesa pode e deve se aliar à tecnologia. Ao se envolver com a leitura e escrita no universo virtual, o aluno pode ampliar seu acervo de conhecimentos, adquirindo habilidades para construir sentidos a partir de hipertextos e, dessa forma, desenvolver multiletramentos. Nesse cenário, os sujeitos são motivados a relacionarem mídias distintas, trocarem informações e atuarem como protagonistas de seu desenvolvimento.

Como afirmam Cope e Kalantzis (2000), o letramento multimodal é de fundamental importância para a inserção do indivíduo em um mundo onde significados emergem de maneira translocal, multicultural e híbrida. Dessa forma, o ensino, ainda que remoto, deve buscar formar alunos capazes de compreender, produzir e transformar significados linguísticos, visuais, de áudio, gestuais e espaciais nos diversos campos de atuação da sociedade atual, que é, reconhecidamente, multimodal, haja vista que os recursos visuais são comuns e a imagem serve como simulação do mundo real, ilustrando discursos, visões ou posicionamentos.

É importante ressaltarmos também o papel do professor neste contexto, que continua sendo essencial, mesmo que os alunos estejam realizando suas atividades em casa. A escolha das tecnologias a serem utilizadas precisam levar em conta também as dificuldades enfrentadas pelos docentes, tais como problemas de rede e acesso, falta de motivação e questões de ordem psicológica. $O$ acúmulo de papéis a serem desempenhados em um ensino de estrutura remota também é algo que deve ser observado, para que não haja um excesso de responsabilização da figura do professor, o que pode ser alcançado com a atribuição, de forma clara, de funções a serem desempenhadas por cada indivíduo envolvido no processo de ensino remoto, garantindo, assim, um ambiente de trabalho favorável ao professor, para que tenhamos um ensino de qualidade em qualquer instância formativa.

A participação dos pais dos alunos nas atividades escolares, embora de extrema importância, não deve colocar em xeque a autonomia docente. $O$ professor necessita, ainda mais nesse momento, ter suas prerrogativas profissionais preservadas, não podendo estar suscetível a julgamentos e avaliações, muitas vezes, descabidos.

A desigualdade social existente entre os alunos da educação básica também precisa ser levada em conta na escolha das tecnologias a serem utilizadas e das atividades a serem desenvolvidas, baseando-se em estratégias que reconheçam as limitações do ensino a distância, para que não sejam penalizados, principalmente, aqueles alunos que se encontram em uma situação de maior vulnerabilidade. A saúde mental, tanto do aluno quanto do professor, deve também ser levadas em consideração ao elencar as estratégias a serem utilizadas.

Buscando contribuir com o ensino remoto de Língua Portuguesa, sugerimos uma proposta de trabalho que visa reunir os estudos da Linguística Aplicada com as possibilidades de ações comunicativas no ambiente da internet, favorecendo o debate sobre o ensino do componente curricular Língua Portuguesa e novas tecnologias e sobre teoria e prática no cotidiano escolar, refletindo sobre suas possibilidades e limitações.

Acreditamos que é preciso focar inicialmente em amenizar os danos a curto prazo, para que, na volta das aulas presenciais, seja possível enfrentar os grandes desafios educacionais que se apresentarão e perdurarão por um prazo ainda indefinido.

\section{REFERÊNCIAS}

BAKHTIN, M. Estética da criação verbal. São Paulo: Martins Fontes, 2003. 512 p.

BAKHTIN, M/VOLOCHINOV, V. Marxismo e filosofia da linguagem. São Paulo: Hucitec, 2004. 203 p. 
BRASIL. Ministério da Educação. Base nacional comum curricular. Brasília, DF. MEC, 2017. Disponível em:

http://basenacionalcomum.mec.gov.br/documento/BN CCAPRESENTACAO.pdf . Acesso em: 25 abr. 2020

BRASIL. Todos pela educação. Nota técnica Ensino a distância na educação básica frente à pandemia da Covid-19. Versão para debate e em contínua construção.Todos pela Educação, 2020. Disponível em: https://www.todospelaeducacao.org.br/_uploads/_post s/425.pdf?1730332266=. Acesso em: 25 abr. 2020.

BARROS, Kazue Saito Monteiro de; CRESCITELLI, Mercedes Fátima de Canha. Prática docente virtual e polidez na interação. In: MARQUESI, Sueli C.; ELIAS, Vanda M. da S.; CABRAL, Ana Lúcia T. (Org.). Interações virtuais. Perspectivas para o ensino de Língua Portuguesa a distância. São Carlos, SP: Claraluz, 2008. 208 p.

CAMAS, Nuria Pons Vilardell. Revisão Teórica da Ação Pedagógica Virtual. RevistaEduca Online. Vol.6 no. 1 Rio de Janeiro Jan./Abril 2012.

COPE, B.; KALANTZIS, M. Multiliteracies: Literacy learning and the design of social futures. London: Routledge, 2000.

DESCARDECI, M. A. S. Ler o mundo: um olhar através da semiótica social. Revista Educação Temática Digital - Campinas, v. 3, n. 2, p. 19-26, jun, 2002.

DIONISIO, Angela Paiva. Multimodalidade discursiva na atividade oral e escrita. In: MARCUSCHI, L. A.; DIONÍSIO, A. P Fala e Escrita.. Belo Horizonte: Autêntica, 2005, p. 177-196.

DIONISIO, Ângela Paiva. Gêneros multimodais e multiletramentos. In: KARWOSKI, Acir Mário et al (org.). Gêneros textuais: reflexão e ensino. 3.ed. - Rio de Janeiro: Nova Fronteira, 2010. 200 p.
GEE, J. P. Lo que nos enseñan los videojuegos sobre el aprendizaje y el alfabetismo. Ediciones Aljibe: Málaga, 2004. 274 p.

KAMENETZ, A. Children Are Out Of School Worldwide. What Now?. National Public Radio. Disponível em:

https://www.npr.org/2020/04/02/824964864/nine-outof-10-of-the-world-s-children-areout-of-school-whatnow. Acesso em 06/04/2020.

LÈVY, P. As tecnologias da inteligência - o futuro do pensamento na era da informática. Trad. Carlos Irineu da Costa, Rio de Janeiro: Ed. 34, 1993.

LEMKE, J. L. Letramento Metamidiático: Transformando significados e mídias. Trabalhos em Linguística Aplicada, vol. 49, no. 2, p. 455-479, Jul./Dez. 2010.

MAGNANI, Luiz Henrique Um passo para fora da sala de aula: novos letramentos, mídias e tecnologias. In: Revista X. Curitiba, v.01, p. 1-18, 2011.

MARCUSCHI, Luiz Antônio. Oralidade e Letramento. In: MARCUSCHI, Luiz Antônio. Da fala para a escrita - Atividades de Retextualização. 4. ed. São Paulo: Cortez, 2003. 133 p.

MARCUSCHI, Luiz Antônio. Da fala para a escrita: atividades de retextualização. 8.ed. São Paulo: Cortez, 2007. 136 p.

MARCUSCHI, Luiz Antônio. Gêneros textuais: configuração, dinamicidade e circulação. In: KARWOSKI, A. M.; GAYDECZKA, B.; BRITO, K. S. (Orgs.). Gêneros Textuais: reflexões e ensino. 4. ed. São Paulo: Parábola Editorial, 2011.p. 17-31.

MILLER, C. R. Estudos sobre gênero textual, agência e tecnologia. Recife: PPGL-UFPE, 2009. 232 p. 
ROJO, R. Multiletramentos na escola. São

Paulo: Ed. Parábola, 2012. 264 p.

SOUTO, D. L. P.; BORBA, M. C. Seres

humanos-com-internet ou internet-com-seres

humanos: uma troca de papéis? Revista

Latinoamericana de Investigación en Matemática

Educativa, Mexico, v. 19, n. 2, p. 1-14, jul. 2016.

UNESCO. Global Monitoring of school closures caused by COVID-19. Disponível em:

https://en.unesco.org/themes/education-

emergencies/coronavirus-school-closures. Acesso

em: 08 abr. 2020.

UNICEF. Covid-19: Mais de 95\% das crianças estão fora da escola na América Latina e no Caribe.

Disponível em:

https://www.unicef.org/brazil/comunicados-de-

imprensa/covid-19-mais-de-95-por-cento-das-

criancas-fora-daescola-na-america-latina-e-caribe.

Acesso em: 23 mar. 2020.

VALENTE, José Armando. Informática na

educação no Brasil: análise e

contextualização histórica. In: VALENTE, José

Armando (org.). O Computador na

Sociedade do Conhecimento. Campinas :

UNICAMP / NIED, 1999, pp. 01-27.

DE CARVALHO, Ive Marian; RIBEIRO, Pollyanne Bicalho. O ensino remoto de língua portuguesa na educação básica frente à pandemia da covid-19: perspectivas e possibilidades. Signo, Santa Cruz do Sul, v. 46, n. 85, p. 15-25, jan. 2021. ISSN 1982-2014. Disponível em: <https://online.unisc.br/seer/index.php/signo/article/view/15563>. doi:https://doi.org/10.17058/signo.v46i85.15563. 